\title{
EDITORIAL
}

\section{Chemistry at the University of Geneva}

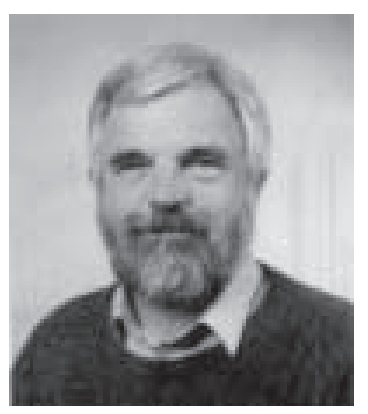

Peter Kündig

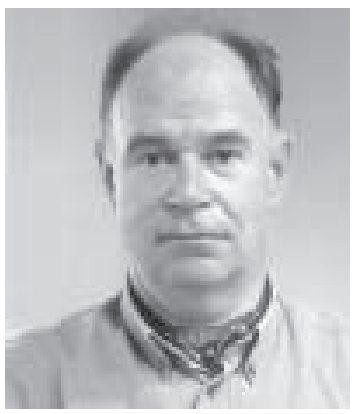

Alan Williams

It is exactly two hundred years since the Académie de Genève created its first three chairs of chemistry in 1802, so chemistry at the University of Geneva is entering its third century. From the first three chairs (of chemistry and natural history, pharmaceutical chemistry, and chemistry applied to the arts) the school of chemistry has grown to over twenty research groups covering a wide range of subjects. The first 200 years have seen a number of important discoveries, including two chemical elements (gadolinium and ytterbium) and have been accompanied by the growth of active chemical and pharmaceutical industries in the Geneva area. Apart from international leaders in the field of fragrance and flavour chemistry (Firmenich SA and Givaudan SA), pharmaceuticals (Ares Serono SA), and materials (Du Pont de Nemours $\mathrm{SA})$, the multinationals Procter \& Gamble and Dow operate in Geneva, and there is a multitude of smaller companies active in research and production.

It is not our intention to review all two hundred years of activity in chemistry, but it is perhaps of some interest to analyse the evolution of the chemistry section since the last issue of CHIMIA devoted to it in 1992, for the changes in the past ten years have been considerable. Over half the professorial staff has been changed, with 14 departures and nine new appointments, the net loss being a consequence of the period of economic restriction experienced by the university. This shortfall has been to some extent compensated, at least in research, by the appointment of a number of younger chemists and biochemists to junior positions, either as maître assistant (non-tenured) or maitre d'enseignement et de recherche (MER, tenured), allowing them to begin independent research careers. This programme, which it would now be fashionable to call a tenure track scheme, has been very successful and no less than five maitre assistants have now obtained professorial positions either inside the chemistry section or elsewhere.

A second major change has been a certain reorientation of research directions: the degree in applied chemistry, which dated back to the first chairs of chemistry in Geneva, was discontinued in 1992, to avoid duplication with the Ecole Polytechnique Fédérale de Lausanne (EPFL) which continues to offer a diplôme d'ingénieur chimiste. Analytical chemistry has been focussed strongly onto the environment. In general there has been a certain concentration of research within the different departments, which we discuss in more detail below. While this means that certain areas are no longer covered by research groups, it also ensures that the 'critical mass' for active research programmes can be maintained. The excellent collaboration with our colleagues in Lausanne (strengthened by the Troisième cycle organisation) has enabled the avoidance of duplication of research directions. Furthermore, the sharing of lecture courses at an advanced level allows our students to acquire a broad vision of their subject.

The final change has been in the study programme: for many years Geneva has been unusual in Switzerland in that the biochemistry department has been part of the chemistry section. Biochemists thus receive a very solid training in chemistry, while in return, all chemists follow biochemistry as part of their training. This tronc commun for the first two years is a particularity of the Geneva programme which becomes all the more important as the overlap between chemistry and biology increases, but which also recalls the earliest chair of 'chemistry and natural history'. In the latest revision of the study programme a student chooses between chemistry and biochemistry at the end of the second year of study. The third year has a defined programme, but the fourth year offers the student a wide choice of subjects, with the possibility of selecting courses from both the University of Geneva and the EPFL.

Chemistry and biochemistry at the University of Geneva are associated in the section of chemistry which assumes responsibility for the study programmes and common facilities such as the library. There are four departments: Biochemistry; Inorganic, Analytical and Applied Chemistry; Organic Chemistry; 
Physical Chemistry. The departments are responsible for specific aspects of teaching and research facilities common to its research programmes. The structure is however flexible, and interdepartmental collaboration is frequent. Forty to fifty new students begin undergraduate studies every year, and an average of twenty five doctorates are awarded annually. The section has approximately 50 post-doctoral fellows.

The department of Biochemistry has groups working on intracellular transport and dynamics (Prof. Jean Gruenberg and Prof. Howard Riezmann), molecular neurobiology (Prof. Ballivet), structural biochemistry and functional modelling of receptors (Prof. Stuart Edelstein) and calcium proteins (Dr. Jos Cox, MER). Prof. Ulrich Laemmli holds a chair shared with the department of Molecular Biology, and studies structural, dynamic, and functional aspects of chromosomes. By virtue of its interdisciplinary nature, this department has strong contacts with cellular and molecular biology and with the Faculty of Medicine.

The department of Inorganic, Analytical and Applied Chemistry has two main poles of activity: analytical chemistry and the chemistry of environmental processes, and inorganic and applied chemistry. The first pole consists of four research groups, concerned with the study of the circulation of trace compounds in aquatic media and the development of new in situ sensors (Prof. Jacques Buffle), the study of speciation and bioavailability of trace elements in natural waters (Dr. Kevin Wilkinson, MER), the study of colloids and polymers and natural porous materials (Prof. Michal Borkovec), and the simulation of physicochemical processes in natural waters, involving polymers and particles (Dr. Serge Stoll, MER). In inorganic and applied chemistry there are three research groups: the synthesis and characterization of nanocrystalline metal oxides and the study of their photochemical and electrochemical properties (Prof. Jan Augustynski), the supramolecular chemistry of f-elements including luminescent sensors and liquid crystals (Prof. Claude Piguet), and self-assembly and crystal engineering of transition metal complexes (Prof. Alan Williams).

The department of Organic Chemistry has a strong interest in asymmetric synthesis and catalysis: chiral auxiliaries, organocopper chemistry and natural product synthesis (Prof. Alexander Alexakis), chiral ligands and organotransition metal chemistry (Prof. E. Peter Kündig), and asymmetric catalysis using carbenes and nitrenes (Prof. Paul Müller). The second major axis of the department is supramolecular chemistry involving asymmetric molecular recognition and supramolecular catalysis (Prof. Jérôme Lacour) and bioorganic chemistry covering the study of molecular rods capable of forming barrels, tubes and of forming pores in biological membranes (Prof. Stefan Matile). Other fields studied include the applications of NMR to organic chemistry (Prof. Ulrich Burger) and the theoretical study of reaction mechanisms by quantum mechanical methods (Dr. Jiri Mareda, MER).

The research activities of the Physical Chemistry department are focussed on three main topics, computational chemistry, the study of the structure and molecular reactivity by spectroscopic methods, and geochemistry. Computational chemistry is centred on Density Functional Theory (DFT) and includes the development of methodology in traditional DFT together with applications in organometallic and surface chemistry (Prof. Jacques Weber and Dr. Pierre Yves Morgantini, MER), and the theoretical treatment of embedded systems (Dr. Tomasz Wesolowski, MER). Three groups are active in the field of spectroscopy, covering the identification and the structure of paramagnetic intermediates by means of EPR/ENDOR spectroscopy (Prof. Michel Geoffroy and Dr Théo Berclaz, MER), the study of molecular reactivity using time-resolved optical spectroscopy (Prof. Eric Vauthey) and the investigation of the structure of transition metal complexes by optical spectroscopy (Prof. Andreas Hauser and Dr. Hans Hagemann, MER). The activity of the Mass Spectroscopy Laboratory (Prof. Fazil Gülaçar), is oriented towards organic geochemistry, more particularly to the diagenetic transformation of biogenic molecules.

The following articles in this edition illustrate the research activities of some of the groups of the section. Rather than attempt to squeeze a description of every research group's activity into a limited number of pages, we have invited the more recently arrived members of staff to present their work. The other members of the section are of course equally active and details of their research may be found on the section's web page http://www.unige.ch/sciences/chimie/. We hope that you will enjoy this selection.

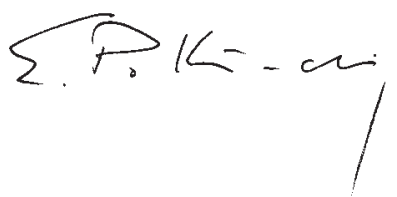

A. I. Williams 